\title{
Engaging the next generation of editorial talent through a hands-on fellowship model
}

\author{
Bridget Deemer ${ }^{1}$, Scott Hotaling ${ }^{2}$, Kelsey Poulson-Ellestad ${ }^{3}$, Laura Falkenberg ${ }^{4}$, James \\ Cloern $^{1}$, and Patricia Soranno ${ }^{5}$ \\ ${ }^{1}$ US Geological Survey \\ ${ }^{2}$ Washington State University \\ ${ }^{3}$ Roosevelt University \\ ${ }^{4}$ The Chinese University of Hong Kong \\ ${ }^{5}$ Michigan State University Clinical and Translational Sciences Institute
}

March 11, 2021

\begin{abstract}
Peer-review and subject-matter editing is the backbone of scientific publishing. However, early career researchers (ECRs) are given few opportunities to participate in the editorial process beyond reviewing articles. Thus, a disconnect exists: science needs high-quality editorial talent to conduct, oversee, and improve the publishing process, yet we dedicate few resources to building editorial talent nor giving ECRs formal opportunities to influence the publishing landscape from within. Here, we describe a "two-way" fellowship model that gives ECRs a "seat" at the editorial table of a field-leading journal. We describe both the necessary framework and benefits that can stem from editorial fellowships for ECRs, editors, journals, and the scientific community.
\end{abstract}

\section{Engaging the next generation of editorial talent through a hands-on fellowship model}

Bridget R. Deemer ${ }^{1 . *}$, Scott Hotaling ${ }^{2 * *}$, Kelsey Poulson-Ellestad ${ }^{3}$, Laura J. Falkenberg ${ }^{4}$, James E. Cloern $^{5}$, and Patricia A. Soranno ${ }^{6}$

\section{Affiliations:}

${ }^{1}$ Southwest Biological Science Center, U.S. Geological Survey, Flagstaff, AZ, USA; Raelyn Cole Editorial Fellow, 2020-2022; ORCID: 0000-0002-5845-1002

2 School of Biological Sciences, Washington State University, Pullman, WA, USA; Raelyn Cole Editorial Fellow, 2019-2021; ORCID: 0000-0002-5965-0986

${ }^{3}$ Department of Biological, Physical, and Health Sciences, Roosevelt University, Chicago, IL, USA; Raelyn Cole Editorial Fellow, 2018-2020; ORCID: 0000-0002-1099-4219

${ }^{4}$ Simon F.S. Li Marine Science Laboratory, School of Life Sciences, The Chinese University of Hong Kong, Hong Kong SAR; Raelyn Cole Editorial Fellow, 2017-2019; ORCID 0000-0002-5868-2310

${ }^{5}$ U.S. Geological Survey, Menlo Park, CA, USA; Editor-in-Chief, Limnology and Oceanography Letters ; ORCID: 0000-0002-5880-6862

${ }^{6}$ Department of Fisheries and Wildlife, Michigan State University, East Lansing, MI, USA; Founding Editorin-Chief,Limnology and Oceanography Letters : ORCID: 0000-0003-1668-9271 
* Contributed equally

Correspondence:

Patricia A. Soranno, Michigan State University; Email:soranno@msu.edu

Authorship statement: B.R.D. and S.H. wrote the first draft of the manuscript and all authors contributed substantially to revisions. P.A.S. conceived of the essay.

Data statement: No data were used to write this article.

Number of words: 1,974

Number of figures/tables/boxes: 2 (figures)

\begin{abstract}
:
Peer-review and subject-matter editing is the backbone of scientific publishing. However, early career researchers (ECRs) are given few opportunities to participate in the editorial process beyond reviewing articles. Thus, a disconnect exists: science needs high-quality editorial talent to conduct, oversee, and improve the publishing process, yet we dedicate few resources to building editorial talent nor giving ECRs formal opportunities to influence the publishing landscape from within. Here, we describe a "two-way" fellowship model that gives ECRs a "seat" at the editorial table of a field-leading journal. We describe both the necessary framework and benefits that can stem from editorial fellowships for ECRs, editors, journals, and the scientific community.
\end{abstract}

\title{
The publishing landscape and early career researchers
}

Challenges in scientific publishing are as diverse as they are complex, ranging from navigating the line between scientific rigor and the rising popularity of pre-prints (Kaiser 2017), issues of equality and bias in publishing (Tomkins et al. 2017; Hofstra et al. 2020), limitations of metrics that evaluate research and researcher impact (Statzner \& Resh 2010; Berenbaum 2019), and challenges of data availability and reproducibility (Pampel \& Dallmeier-Tiessen 2014). Many publishing challenges also disproportionately affect early career researchers (ECRs) - e.g., concerns about impact factor for job applications (Berenbaum 2019) and biases in peer review (Tomkins et al. 2017). Still, the current publishing framework places more senior scientists in charge of decision-making and establishing editorial policies (Schäfer et al. 2011), despite the fact that ECRs are often on the leading edge of science and publishing trends and can therefore provide key insight to journals seeking to navigate quickly changing editorial waters. For example, ECRs are more likely than their senior colleagues to view the emerging practice of posting 'pre-prints' prior to manuscript submission favorably (Soderberg et al. 2020); and, ECRs are six times more likely to make their data public (Campbellet al. 2019). Here, we argue that ECR editorial fellowships designed around a two-way knowledge exchange benefit not only the ECRs, but also journals, publishers, and the broader scientific community through their unique perspectives on scientific publishing.

Despite the potential value of ECR participation, efforts to formally integrate ECRs into editorial processes, beyond simply serving as reviewers, have been limited. A few examples of editorial internships at medical journals exist (e.g., American Society of Clinical Oncology), and these opportunities provide a structured framework for ECRs to learn more about the process (Hopkins 2018). In the life sciences, an editorial internship at the ICES Journal of Marine Science was recently created to aid ECRs in publishing with that journal and more broadly (Howard Browman, pers. comm.). To our knowledge, the primary motivation for these internship-type programs is a "one-way" training model where ECRs gain exposure to the publishing process and build their scientific networks. While still valuable to ECRs, a "one-way" framework does not necessarily provide opportunities for ECRs to engage with, and ultimately influence, publishing processes at their focal journal and beyond.

The Raelyn Cole Editorial Fellowship: a case study in "two-way" ECR engagement 
Here, we describe an alternative model for an ECR editorial program that emphasizes two-way engagement between ECRs and publishers, editorial boards, and the scientific community. In this model, Fellows are integrated beyond the peer review process into all aspects of publishing and editing. They contribute intellectually through Fellow-led initiatives and input to decision-making and journal policy. This fellowship model views ECRs in the same way that the broader scientific community views postdoctoral researchers - highly experienced, independent, early-career colleagues with the potential to dramatically shape the conversations and projects they are involved in. We used this model to develop the Raelyn Cole Editorial Fellowship (RCEF; Soranno and Falkenberg 2018) for the journal Limnology 83 Oceanography Letters, a short-format, open-access Association for the Sciences of Oceanography and Limnology (ASLO) journal founded in 2014 (Sorannoet al. 2021).

RCEF Fellows serve a two-year term and receive a $\$ 1,500$ annual stipend, travel support to attend one society meeting per year, and an invitation to an annual strategy day with the journal publisher, Wiley. Fellow terms are staggered to ensure that there are always two Fellows which fosters collaboration and relationship-building within the fellowship cohort. The Editor-in-Chief (EIC) of Limnology 83 Oceanography Letters makes the most significant commitment to the RCEF program. The Fellows and EIC meet monthly to discuss day-today workings of the journal and discuss current and future Fellow initiatives. These initiatives span (but are not limited to): scholarly articles, workshops, editorial programming, and outreach. Importantly, the RCEF provides a supportive, collaborative space for Fellows to develop initiatives based on their interests. While all RCEF Fellows receive the same opportunities for engagement with editors and publishing partners, no two fellowships are the same because no two Fellows have the same background, interests, and professional goals.

\section{Benefits of a two-way editorial fellowship}

Beyond the obvious benefits to Fellows in terms of career development and networking, a two-way editorial fellowship model also holds tremendous value for editors, journals (including publishers), professional societies, and the global scientific community (Fig. 1). For example, RCEF Fellows have made a number of scholarly contributions that benefit a wide range of researchers including: examining the demographics and career trajectories of Associate Editors (Poulson-Ellestad et al. 2020); creating workshops to connect ECRs with journal editors (Deemer et al. 2020); describing ways to be a better peer reviewer (Falkenberg \& Soranno 2018); and improving manuscript preparation through writing guides (Hotaling 2020) and organizing workshops. From a publisher's perspective, "opportunities to integrate ECRs into publishing are valuable since the sustainability and success of journals heavily relies on the big and bold ideas voiced by the next generation of researchers" (Fiona Sarne, Wiley, pers. comm.). From a scientific society perspective, editorial fellowships distribute leadership beyond senior and mid-career scientists, involve ECRs in key discussions, and foster fun and creative discussions between editors, Fellows, and the society membership that build community (Mike Pace, former ASLO President, pers. comm.). At the global level, resources produced by ECRs directly benefit the scientific community but equally important is the behind-the-scenes role that ECRs can have in driving editorial change.

While all RCEF products have benefited multiple groups, some efforts have captured benefits that stretch from the Fellow to the global scientific community. For example, a practical guide to concise scientific writing (Fig. 2a; Hotaling 2020) emerged from a Fellow's own early struggles with writing and manuscript preparation. This essay has been downloaded $>50,000$ times since June 2020. Such strong resonation with the scientific community, far beyond the typical reach of articles in Limnology $\&$ Oceanography Letters , has spurred the EIC to solicit similar articles targeting key scientific issues with wide relevance.

Another example is an early career publishing honor (Fig. 2b) which was conceived by RCEF Fellows during a discussion with the EIC at an annual publishing strategy meeting. The honor was created to address two needs for the journal identified by the EIC: increasing submissions to a still relatively new journal, and increasing the geographic and topical diversity of submissions. It also addressed a need that the Fellows identified: making open access publication more accessible to financially limited ECRs. Fellows developed a rubric to score applications based on criteria they deemed most important: (1) scientific novelty and interest, 
(2) potential to support under-represented groups (broadly defined), (3) journal fit, and (4) financial need. Beyond the benefits to awarded researchers, the program provided an opportunity for Fellows to think like editors by considering research beyond their own expertise, making difficult decisions, and providing feedback on manuscripts ahead of submission.

\section{What is needed to create an impactful editorial fellowship?}

While there are likely many ways to support ECRs through editorial training, we consider the collaborative, two-way model of the RCEF to be the most crucial key to its success (Fig. 1). By providing a supportive framework for ECRs to pursue the aspects of the editorial process they find most compelling, the program and its beneficiaries can best capitalize on the strengths of each Fellow. However, this framework cannot succeed without initiative from the Fellows and a willingness to commit time to the program from both the Fellows and EIC. Beyond the Fellows, it is also crucial that the EIC, journal, publishing partner, and scientific society (if applicable) actively support diverse ECR perspectives. For the RCEF, this higher-level support is shown by inviting Fellows to strategy meetings, the EIC seeking Fellow opinions on editorial and journal policy decisions, and by listening when a Fellow gives feedback or makes a suggestion. In addition to the two-way model, we consider the creation and maintenance of an inclusive environment with a goal of broadening participation at every turn to be fundamental to the success of any fellowship program. By prioritizing diversity and inclusion, an editorial fellowship can help journals keep pace with the increasingly global, connected state of academic research while also giving an important platform to historically excluded voices.

Institutional support at the society and/or publisher level is also important to any fellowship (Fig. 1). For the RCEF, the society (ASLO) supports the program financially (e.g., through stipends, conference fee waivers), publicly via formal acknowledgements (e.g. society-wide correspondences), and professionally (e.g., including Fellows in strategy meetings). The publishing partner, Wiley, supports the program by providing Fellows with key resources for project coordination (e.g., relevant data or technical assistance for workshop development). This support from the society and the publisher show the Fellows that their efforts are valued. This, in turn, raises the caliber of future applicants who see the commitment being made to Fellows and encourages the Fellows to aim high with their fellowship goals.

\section{A successful editorial fellowship is more than numbers}

Perhaps the most difficult aspect of this two-way fellowship model to convey is the personal side; the fun, engaging interactions that broaden horizons and improve the publishing landscape for everyone. This "human side" of the fellowship has been powerful. It has seeded key relationships that we will carry for the rest of our careers and has fundamentally shifted how we collectively view scientific publishing, including the roles of editors, publishers, societies, and ECRs in the process. For the Fellows, we have seen first-hand that editors are not antagonists for authors; if anything, they are the authors' biggest supporters. We Fellows have also gained valuable professional "community" through interactions with our Wiley partners, editors at other journals, authors, and society members. For editors and publishers, the RCEF has provided an eye-opening view into the rich potential for ECRs to influence publishing now since ECRs have a keen sense of urgency surrounding key publishing issues (e.g., the movement towards open, reproducible science). From the EIC perspective, we can summarize our views simply: it has been a privilege and joy to collaborate with editorial Fellows. They give us confidence that the future of scientific publication is in terrific hands.

\section{Conclusion}

In this essay, we described a novel early career editorial fellowship that succeeds through a collaborative, two-way interaction model. We highlighted the potential for editorial fellowships to benefit the scientific community at multiple levels. We advocate for wider implementation of such editorial fellowships to provide key training for ECRs while simultaneously addressing the systemic lack of ECR voices in scientific publishing.

\section{Acknowledgements:}


B.R.D., S.H., K.P.E., and L.J.F. were supported by the RCEF from 2017-present. S.H. was supported by NSF OPP-1906015. We thank Howard Browman, Valerio Bartelino, and Emilie Gunn for their input regarding other editorial training programs. We thank Mike Pace for his support of the RCEF and input from a society's perspective. We thank Teresa Curto for coordinating and managing the financial side of the RCEF. We also thank Wiley, particularly Fiona Sarne and Alice Smith, for their support. Finally, we thank Dale Cole and family for the generous donation that supports the program. Any use of trade, product, or firm names is for descriptive purposes only and does not imply endorsement by the U.S. Government.

\section{References:}

Berenbaum, M.R. (2019). Impact factor impacts on early-career scientist careers. Proc Natl Acad Sci USA , 116, 16659-16662.

Campbell, H.A., Micheli-Campbell, M.A. \& Udyawer, V. (2019). Early Career Researchers Embrace Data Sharing. Trends in Ecology \& Evolution, 34, 95-98.

Deemer, B.R., Hotaling, S., Poulson-Ellestad, K., Falkenberg, L.J. \& Cloern, J.E. (2020). Virtual Networking Between Editors and Early Career Scientists: Benefits, Silver Linings, and Lessons Learned.Limnology and Oceanography Bulletin , 29, 141-144.

Falkenberg, L.J. \& Soranno, P.A. (2018). Reviewing Reviews: An Evaluation of Peer Reviews of Journal Article Submissions.Limnology and Oceanography Bulletin , 27, 1-5.

Hofstra, B., Kulkarni, V.V., Munoz-Najar Galvez, S., He, B., Jurafsky, D. \& McFarland, D.A. (2020). The Diversity-Innovation Paradox in Science. Proc Natl Acad Sci USA , 117, 9284-9291.

Hopkins, C. (2018). ASCO Journals Editorial Fellowship: Equipping Oncologists to Raise the Quality of Published Research on a Global Scale. ASCO Connection .

Hotaling, S. (2020). Simple rules for concise scientific writing.Limnol Oceanogr , 5, 379-383.

Kaiser, J. (2017). The preprint dilemma. Science, 357, 1344-1349.

Pampel, H. \& Dallmeier-Tiessen, S. (2014). Open research data: from vision to practice. In: Opening Science (eds. Bartling, S. \& Friesike, S.). pp. 213-224.

Poulson-Ellestad, K., Hotaling, S., Falkenberg, L.J. \& Soranno, P. (2020). Illuminating a Black Box of the Peer Review System: Demographics, Experiences, and Career Benefits of Associate Editors.Limnology and Oceanography Bulletin, 29, 11-17.

Schafer, R.B., Cooke, S.J., Arlinghaus, R., Bonada, N., Brischoux, F., Casper, A.F., et al. (2011). Perspectives from early career researchers on the publication process in ecology - a response to Statzner \& Resh (2010): Perspectives from early career researchers on the publication process. Freshwater Biology , 56, 2405-2412.

Soderberg, C.K., Errington, T.M. \& Nosek, B.A. (2020). Credibility of preprints: An interdisciplinary Survey of Researchers. MetaArXiv .

Soranno, P.A., Downing, J.A. \& Curto, T.L. (2021). FoundingLimnology \& Oceanography Letters : The challenges, risks, and rewards of launching a new scientific journal. Limnol Oceanogr, lol2.10182.

Soranno, P.A. \& Falkenberg, L.J. (2018). How Editorial Fellowships at Society Journals Can Provide Opportunities for Early Career Researchers in Publishing: A Case Study of the Raelyn Cole Editorial Fellowship.Limnology and Oceanography Bulletin , 27, 88-88.

Statzner, B. \& Resh, V.H. (2010). Negative changes in the scientific publication process in ecology: potential causes and consequences: Scientific publication process in ecology. Freshwater Biology , 55, 2639-2653.

Tomkins, A., Zhang, M. \& Heavlin, W.D. (2017). Reviewer bias in single- versus double-blind peer review. Proc Natl Acad Sci USA, 114, 12708-12713. 
Figures and Figure Legends:

What are the benefits?

\begin{tabular}{|c|c|c|}
\hline \multicolumn{3}{|c|}{ ECRs driving change in publishing and gaining editiorial training } \\
\hline Experience & ECR support & ECR interest \\
\hline Networking & New, creative input & Production of resources for ECRs in writing and publishing \\
\hline Financial support & Signal of ECR support to broader community \\
\hline \multicolumn{2}{|c|}{ Potential for identifying, supporting, and integrating diverse ECRs into edtorial boards } \\
\hline Fellows
\end{tabular}

What is needed?

\begin{tabular}{|c|}
\hline \multicolumn{2}{|c|}{ An open-minded, inclusive, and collaborative approach } \\
\hline Willingness to commit time \\
\hline Initiative \\
\hline Editorial interest \\
\hline Publishing exper.
\end{tabular}

Figure 1. The benefits (green bars on top) and requirements (red bars below) of a two-way early career editorial fellowship program. Groups that contribute to or benefit from the program are pictured in five categories in the center of the panel. Here, society refers to a professional society. Horizontal bars overlap the groups that are impacted by the requirement or benefit. In the bottom panel, needs are loosely ranked from least (lighter shading) to most (darker shading) important. 
a LiMNOLOGY AND OCEANOGRAPHY

\section{ESSAY}

Simple rules for concise scientific writing
- 52,000 downloads since June 2020 .

- Highest all-time Altmetric score for Limnology \& Oceanography Letters.

- Inspired a new article series aimed at training in writing, statistics, and more.

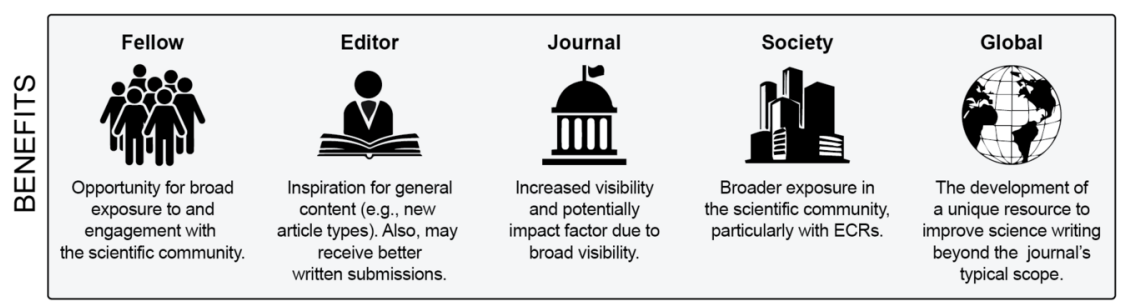

\section{b L\&O Letters Early Career Publication Honor - Call for Applicants}

- 71 applicants from 19 countries.

- Raised global awareness of the journal.

- Provides an open-access publishing opportunity for 13 ECRs.

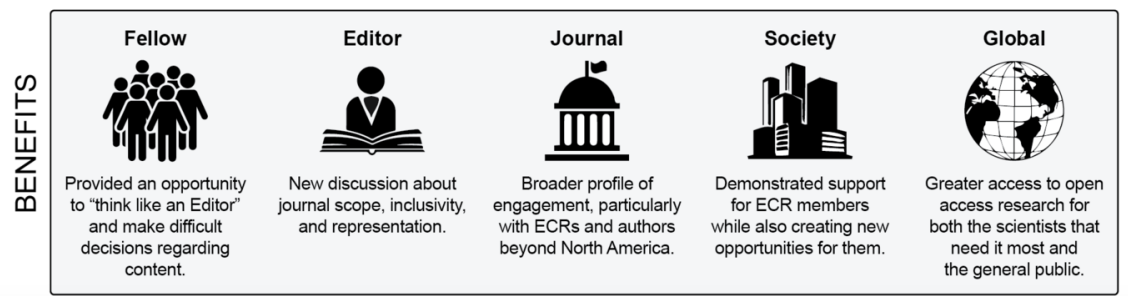

Figure 2. Two case studies of outputs from the RCEF that highlight the benefits of a two-way fellowship model where Fellows have the space and support to develop their own initiatives. (a) An essay devoted to concise scientific writing (Hotaling 2020). (b) A publication honor to support ECR research. Both initiatives were conceived and executed by Fellows with support from multiple levels of the publishing enterprise. 